\title{
ACE-gene polymorphism, particularly "D/I", may play a role in the occurrence of COVID-19 pneumonia in hypertensive elderly patients
}

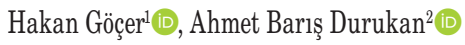 \\ ${ }^{1}$ Department of Cardiology, Medical Park Uşak Hospital, Uşak, Turkey \\ ${ }^{2}$ Department of Cardiovascular Surgery, Medical Park Uşak Hospital, Uşak, Turkey \\ Received: April 07, 2020 Accepted: April 12, 2020 Published online: May 18, 2020
}

Renin-angiotensin-aldosterone system has an important role in the pathophysiology of high blood pressure. ${ }^{[1]}$ Also, angiotensin II and bradykinin are vasoactive molecules with multiple acute and chronic effects on the cardiovascular system. ${ }^{[1,2]}$ As stated in recent reports, COVID-19 pneumonia more frequently occurs in COVID-19-positive hypertensive elderly. ${ }^{[2]}$ To the best our knowledge, COVID-19 pneumonia has a grave prognosis in hypertensive and elderly patients. Angiotensin-converting enzyme (ACE) genotype has been blamed for this course, and although the interaction between COVID-19 and $\mathrm{ACE}$ receptors interaction has been well defined, ACE genotype polymorphism has not been fully elucidated, yet. ${ }^{[3]}$ In this infection, many researches and reports have shown the effect of ACE insertion deletion (I/D) gene polymorphism on risk, prognosis, and reaction to treatment of many diseases such as hypertension, heart failure, myocardial infarction, diabetes, diabetic nephropathy, and cancer. ${ }^{[3]}$ It is well-known that ACE gene is located on chromosome 17 and polymorphism consists of three types within the intron 16 (DD, ID, II) and depends on heredity, ethnicity, and geographical considerations. ${ }^{[4]}$ Furthermore, D/I type has been found more frequently in hypertension, diabetes, and myocardial infarction. ${ }^{[4]}$ Prognosis is more grave in this genotype polymorphism. Our suggestion is that $\mathrm{D} / \mathrm{I}$ type ACE gene polymorphism should be a research of interest for predicting prognosis and propensity of COVID-19 infection in hypertensive elderly patients.

\section{Declaration of conflicting interests}

The authors declared no conflicts of interest with respect to the authorship and/or publication of this article.

\section{Funding}

The authors received no financial support for the research and/or authorship of this article.

Corresponding author: Ahmet Barış Durukan, MD. Medical Park Uşak Hastanesi Kalp ve Damar Cerrahisi Bölümü, 64200 Uşak, Türkiye.

Tel: +90 532 - 2273814 e-mail: barisdurukan@yahoo.com

\section{Citation:}

Göçer H, Durukan AB. ACE-gene polymorphism, particularly "D/I", may play a role in the occurrence of COVID-19 pneumonia in hypertensive elderly patients. Cardiovasc Surg Int 2020;7(1):39. 